\title{
Statistical variability of top ranking economics journals impact
}

\author{
PEDRO COSME COSTA VIEIRA
}

Faculdade de Economia do Porto, R. Dr. Roberto Frias, s/n, 4200-464 Porto, Portugal

E-mail:pcosme@fep.up.pt

Four issues concerning the quality of scientific economics papers are addressed. First, the ex-ante procedure of computing the average impact of economic papers are validated by comparing its results with the ex post values. Second, an estimator of papers normalized impact is calibrated. Third, the ranking variability of journals is computed using a bootstrap procedure. Fourth, the statistical hypothesis that journals' ranking did not change over the time interval between 1980 and 2000 is tested. It is concluded that this hypothesis is rejected only for the Quarterly Journal of Economics and Econometrica, which saw their citation impact improved.

\section{INTRODUCTION}

The scientific community accepts that its output must be quantified so that scarce resources may be efficiently allocated, including the evolution of investigators' career. Influenced by the long USA's tradition of using scientific journals as the main means of knowledge exchange, all over the world it is becoming standard to use the quantity of papers published in these journals as the primary measure of output.

But scientific papers are not a homogeneous product, making it necessary to take into account the quality. Given that the objective of publication is the diffusion of knowledge, it is natural that only papers with high quality will be used as base for other papers that will cite them (see, Laband and Sophocleus, 1985). Since it is impossible to know at present what will be the future impact of papers published today, one practical methodology is to assume the average quality of the journal (its impact) as a proxy for the expected papers' quality.

In the 1970s two procedures emerged for quantifying the quality of scientific journals based both on counting the present citation of past papers (Moore, 1972), and on asking the opinion of selected economists, (Hawkins et al., 1973).

As the impact of a journal increases proportionally with its dimension, without indicating an increase in papers average quality, it is necessary to weight the impact of journals by the number of papers published each year. This procedure, performed by Liebowitz and Palmer (1984), computes the average relative impact of each paper published. In the 1990s and 2000s there are numerous replications of Liebowitz and Palmer's (1984) work, either applied to economics (e.g., Laband and Piette, 1994; Barrett et al., 2000; and Kalaitzidakis et al., 2003) or to other disciplines (e.g., Holsapple et al., 1994).

In this paper the intension is to address four new issues related to the measure of papers' quality. First, the average impact estimation procedure of Liebowitz and Palmer (1984) is evaluated by comparing the ex-ante results computed in Laband and Piette (1994) with the ex post average papers' impact. Second, an estimator of the impact of a single paper is calibrated - it is a more accurate estimator of the papers quality than to use the journals average impact where they are published. Third, the statistical variability of a journals impact on a yearly base is quantified. Fourth, the journals which average relative impact changed over the past two decades (between 1980 and 2000 ) is tested within a $5 \%$ confidence interval.

In the computation of journals' average impact variability, a bootstrapping procedure (Efron, 1979) is used, implemented in Microsoft Visual Basic 6.0 (TM). Data, datasheets and computer programs are available from the author upon request. 


\section{THE CALCULATION PROCEDURE}

As explained above, when comparing scientific papers it may be assumed that the number of times these papers are cited in other papers is a sign of their quality, especially in ones that are of high quality. If so, the 'correct' way to compute the quality of a scientific paper would be summing up the quality for all papers that cite it. Since this procedure is forward looking it becomes impossible to put it into practice as the impact of today's papers is yet zero. To turn the procedure into a workable one it is necessary to use the average papers quality of a journal instead of the quality of future papers that cite it (excluding or not citations in the same journal). This method is halfway between the Liebowitz and Palmer's (1984) procedure and the 'correct' one.

Since it is intended to evaluate Liebowitz and Palmer's (1984) procedure, the 20 top ranking economic journals of Laband and Piette's (1994, Table 2, column 3 was selected). Those missing in the list were completed with the 20 top ranking economic journals of Kalaitzidakis et al. (2001, Table 1, column 5), excluding Games and Economic Behaviour that does not appear in the 1990 ISI database. In total, 23 economic journals (Table 1, column A) were selected.

Given that the impact of a paper is computed by summing up the average impact of all journals that cite it, it is necessary to have an extended list of journals. For all journals not included in the list used here but that are in Kalaitzidakis et al.'s (2001, Table 1, column 5) an authors' estimation is used. For the Journal of Finance, the Laband and Piette's (1994, Table 2, column 3) estimation of 34.1 is used as impact. For all other journals 0.01 is used, because it is better to be cited in a 'low average quality' journal that not at all.

Table 1, columns B and C, contain the estimations from Laband and Piette's (1994) columns 2 and 3, respectively. Using 32 top journals of Kalaitzidakis et al.'s (2001) the ranking for the year 2000 was computed using the same methodology - papers published since 1995 with no selfcitations (Table 1, column D). Although in the ISI database for the year 2000 shows the Journal of Economic Literature to have only published five papers, after consulting the journal, the number of papers was corrected to 16 .

Data that is available in the ISI site was downloaded for the papers published in those selected 23 economic journals in the year 1990. Data was downloaded during the second half of May 2004 from the ISI Web of Knowledge at www. isi4.newisiknowledge.com. The results showed 1172 papers that were cited 32435 times (on average, each paper was cited 27.7 times).

The time span of 13 years seems adequate because approximately two-thirds of all citations occur 13 years after a paper is published. The evolution of citations was estimated by measuring a bibliographic citation of the 32 top ranking journals of Kalaitzidakis et al. (2003). In a

Table 1. Economic journal's impact and its variability

\begin{tabular}{|c|c|c|c|c|c|c|c|c|c|c|}
\hline A & $\mathrm{B}$ & $\mathrm{C}$ & $\mathrm{D}$ & $\mathrm{E}$ & $\mathrm{F}$ & $\mathrm{G}$ & $\mathrm{H}$ & I & $\mathbf{J}$ & $\mathrm{K}$ \\
\hline Journal & 1980 & 1990 & 2000 & $\begin{array}{l}\text { Ex } \\
\text { post } 1990\end{array}$ & 20’s L. I. P. & $F(x)=2.5 \%$ & $F(x)=97.5 \%$ & $\mathrm{Nm}$ & $\begin{array}{l}\text { Journal } \\
\text { impact }\end{array}$ & $\begin{array}{l}\text { Value for } \\
\text { USS }\end{array}$ \\
\hline Econometrica & 31.60 & 78.40 & 94.11 & 100.00 & 14.75 & 55.88 & 100.00 & 59 & 98.95 & 43.04 \\
\hline J. Pol. Econ. & 59.12 & 63.00 & 75.04 & 99.38 & 10.91 & 52.18 & 100.00 & 60 & 100.00 & 76.04 \\
\hline J. Fin. Econ. & 62.15 & 100.00 & 6.16 & 85.87 & 70.75 & 53.71 & 100.00 & 22 & 31.68 & 4.53 \\
\hline J. Econ. Lit. & 100.00 & 28.80 & 100.00 & 66.99 & 66.99 & 4.38 & 78.71 & 10 & 11.23 & 100.00 \\
\hline Rev. Econ. Stud. & 30.36 & 40.70 & 94.21 & 61.35 & 7.45 & 27.45 & 88.23 & 42 & 43.21 & 31.33 \\
\hline Q.J. Econ. & 16.17 & 41.60 & 68.79 & 44.21 & 7.54 & 23.17 & 58.23 & 49 & 36.33 & 35.91 \\
\hline J. Hum. Resour. & 13.60 & 4.60 & 15.32 & 41.27 & 17.27 & 14.66 & 60.32 & 24 & 16.61 & 20.07 \\
\hline Am. Econ. Rev. & 34.48 & 40.20 & 31.64 & 40.71 & 0.10 & 24.21 & 49.43 & 146 & 99.68 & 100.00 \\
\hline J. Econ. Theory & 22.28 & 34.90 & 44.07 & 36.70 & 2.47 & 18.90 & 48.42 & 54 & 33.24 & 96.39 \\
\hline Economet. Theory & - & - & 13.54 & 34.27 & 34.27 & 11.52 & 57.82 & 19 & 10.92 & 5.00 \\
\hline J. Econometrics & 17.32 & 18.60 & 20.06 & 28.23 & 0.40 & 15.24 & 38.92 & 79 & 37.40 & 3.30 \\
\hline J. Math. Econ. & 24.73 & 20.60 & 9.18 & 28.09 & 28.09 & 5.77 & 21.20 & 19 & 8.95 & 1.30 \\
\hline J. Mon. Econ. & 33.00 & 41.90 & 32.57 & 26.13 & 7.87 & 11.97 & 37.33 & 30 & 13.15 & 1.75 \\
\hline J. Bus. Econ. Stat. & - & 7.90 & 26.24 & 21.84 & 0.13 & 9.18 & 31.91 & 64 & 23.44 & 37.76 \\
\hline J. Econ. Persp. & - & 23.30 & 32.80 & 21.56 & 2.67 & 11.64 & 27.39 & 49 & 17.72 & 100.00 \\
\hline Bell/Rand. J. Econ. & 39.45 & 40.20 & 24.53 & 20.73 & 3.68 & 10.41 & 27.27 & 40 & 13.91 & 15.51 \\
\hline J. Lab. Econ. & - & 15.40 & 18.11 & 20.23 & 5.55 & 8.72 & 26.80 & 36 & 12.21 & 10.79 \\
\hline J. Inter. Econ. & 14.12 & 7.60 & 12.34 & 14.09 & 2.39 & 9.02 & 55.46 & 39 & 9.22 & 1.67 \\
\hline Econ. J. & 14.96 & 7.50 & 14.82 & 13.88 & 0.48 & 6.89 & 18.47 & 73 & 16.99 & 8.38 \\
\hline Inter. Econ. Rev. & 19.04 & 12.30 & 31.04 & 12.34 & 0.18 & 6.26 & 16.09 & 66 & 13.66 & 8.71 \\
\hline J. Pub. Econ. & 19.65 & 8.60 & 11.74 & 10.26 & 0.33 & 6.17 & 14.71 & 66 & 11.36 & 1.22 \\
\hline Rev. Econ. Stat. & 12.40 & 6.50 & 16.70 & 8.44 & 0.73 & 3.63 & 13.22 & 45 & 6.37 & 4.90 \\
\hline Eur. Econ. Rev. & 6.70 & 2.10 & 14.87 & 7.24 & 0.00 & 3.45 & 10.00 & 86 & 10.44 & 2.08 \\
\hline
\end{tabular}


total of 46173 citations of papers published in 2000, approximately $0.20,0.33,0.50,0.67,0.80$ and 0.90 of bibliographic citations were from papers published in the last $3,5,8,13,19$ and 30 years, respectively. Adjusting a polynomial function of degree three, the percentage of paper citations with age until 30 years is

$$
100 \frac{C_{t}}{C_{\infty}}=8.09 \cdot t-0.252 \cdot t^{2}+0.00273 \cdot t^{3},\left(R^{2}=0.9985\right)
$$

(otherwise, $C_{t} / C_{\infty}=0.95$ is used):

In column $\mathrm{E}$ of Table 1 each journal's ex post average impact per paper is shown. Since $Z_{m}$ is the total number of published papers in the journal $m$ during 1990, and $K_{m, n}$ the number of citations of those articles in other papers published in journal $n$ ( $N$ being the total number of journals) then the average journal impact, $I_{m}$, is computed as the sum of all citations in journal $n$ to that $Z_{m}$ papers:

$$
I_{m}=\frac{\sum_{n=1}^{N} K_{m, n} \cdot I_{n}}{\xi \cdot Z_{m}}
$$

In this expression the parameter $\xi$ is a scale factor that normalizes an average papers citation impact to 100 .

As it is intended to exclude self-citations (a paper being cited in the same journal) from the results, that is $m=n$, 0.01 is used for the citations in the same journal (as if it where cited in a 'low average quality' journal). Since Equation 2 has $M+1$ variables, the normalization equation must be added (the ranking of the top average impact journal is normalized to 100 ):

$$
\operatorname{Max}\left\{I_{1}, \ldots, I_{m}\right\}=100
$$

The Equations 2 and 3 represent a non-linear $(M+1)$ equation system that is computed using an iteration method implemented in a computer datasheet (see Moore, 1972). Alternatively it could be used as a relaxation method without loss.

Furthermore, for each journal the average impact of the 20th lowest impact papers is computed (Table 1, column F). This number is important because, more than the average impact, it measures how difficult it is for a 'low quality' paper to be published.

The normalized impact statistical variability was computed using a bootstrapping procedure (Efron, 1979) implemented in Microsoft Visual Basic 6.0 (TM). Because papers published in one year are chosen in uniform by a random process from a pool of papers, the bootstrapping method computes the variability by re-sampling 'volumes' with reposition of the papers. This process was replicated 1000 times by re-sampling the papers published in the 1990s, computing for each new re-sample the average impact of the 23 journals selected. It is shown in columns $\mathrm{G}$ and $\mathrm{H}$ of Table 1 , the $2.5 \%$ and the $97.5 \%$ computed ranking percentiles, respectively.

The 1990s global impact of journals (Table 1, column J) is computed by multiplying each paper's average impact
(Table 1, column E) by the number of papers published in 1990 (Table 1, column I), normalized to 100. Note that in 1990, the Journal of Economic Literature published 10 papers in spite of the ISI database reporting only 6 .

In column $\mathrm{K}$ of Table 1, the journal value for money is computed by dividing the journal impact (Table1, column J) by the 2004s 'institution from OCDE subscription cost' and normalizing the values to 100 . The subscription to Journal of Economic Literature, American Economic Review and Journal of Economic Perspective is combined. Notice that in an OCDE country the 16 top value for money economic journals cost approximately 4000 US\$ per year, while the other seven journals of Table 1 cost approximately three times that value.

\section{STATISTICAL RESULTS}

The first observation is that the Laband and Piette (1994) ranking prediction of 16 journals out of 19 are inside the $95 \%$ interval of average rankings computed (see Table 1, columns $\mathrm{G}$ and $\mathrm{H}$ ). The Journal of Business and Economic Statistics and European Economic Review's prediction are outside (above) this interval. In an opposite direction, the impact of Bell/Rand Economics Journal was ex post lower than predicted. Accepting that these three journals impact has evolved (notice that Journal of Business and Economic Statistics is published only since 1984 and Bell changed the name to Rand), the Liebowitz and Palmer (1984) extension of Moore's (1972) procedure is an adequate procedure to estimate scientific papers' average impact. Moreover, it is conjectured that the Journal of Monetary Economics' impact prediction is out of the ex post interval because its papers are cited in business and finance literature that Laband and Piette (1994) take into account but is not considered here.

The second observation is that the ranking variability of top cited journals is very significant. Notice that the ranking of the five top journals may vary approximately 50 points in a scale of 100 and for all other journals the 2.5 percentile is smaller than half the 97.5 percentile.

Thirdly, for 21 out of 23 journals, the statistical hypothesis that the journals ranking did not change over the time interval between 1980 and 2000 (or between 1990 and 2000 when there is no value for 1980) may not be rejected.

Assuming that the ranking position in years 1980, 1990 and 2000 are random extractions from the statistical variable with identical expected value and standard deviation that may be estimated by the computed percentiles, $S=\left(X_{97.5}-X_{2.5}\right) / K, \mathrm{H}_{0}$ can not be rejected for a significance level of $5 \%$ when

$$
\frac{\left|I_{1980}-I_{2000}\right|}{(2)^{1 / 2} \cdot\left(X_{97.5}-X_{2.5}\right) / K} \leqslant K \Leftrightarrow \frac{\left|I_{1980}-I_{2000}\right|}{\left(X_{97.5}-X_{2.5}\right)} \leqslant(2)^{1 / 2}
$$


The hypothesis $\mathrm{H}_{0}$ is rejected only for the Quarterly Journal of Economics and Econometrica which improved their citation impact.

\section{CALIBRATION OF THE PAPERS IMPACT ESTIMATOR}

The parameter $\xi$ in Equation 2 is a scale factor that permits papers citation impact to be normalized. Excluding citations from papers in the same journal, the $\xi$ value is computed as 8.05, being otherwise 11.29 (except for Journal of Financial Economics that has a large percentage of self-citations). The journal impact must yet be corrected by the paper's age using Equation 1. Since a 13 years time span is used in the estimation of $\xi$, the paper impact must be estimated by the following expression:

$$
I=\frac{\sum_{i=1}^{K_{m}} I_{n}}{\xi \cdot C_{t} / C_{13}}
$$

Because, on average, in the first three years of a paper's 'life' it only receives approximately $1 / 5$ of the long term total number of citations, it seems inadequate to compute a paper's impact previous to three years from the date of publication (the estimation error would be very high).

\section{CONCLUSION}

Given that it is important to quantify a paper's quality, in this study four issues are addressed relating the relative quality (impact) of economic papers. First, it is validated that, although past information is used, the speculative procedure of Liebowitz and Palmer (1984) is a good predictor of an average papers impact. Second, an estimator is calibrated that makes it possible to quantify the quality (impact) of a single paper. Third, it is quantified that the variability of a journal's impact on a year scale is very considerable. Fourth, it is computed that the journals average impact varies considerably from one year to another but the long term 'tendency' does not change to any great extent.

\section{REFERENCES}

Barrett, C. B., Olia, A. and Von Bailey, D. (2000) Subdisciplinespecific journal rankings: whither Applied Economics?, Applied Economics, 32, 239-52.

David, N. L. and Sophocleus, J. P. (1985) Revealed preference for economics journals: citations as dollar votes, Public Choice, 46, 317-23.

Efron, B. (1979) Bootstrap methods: another look at the jackknife, Annals of Statistics, 7, 1-26.

Hawkins, R. G., Ritter, L. S. and Walter, I. (1973) What economists think of their journals, Journal of Political Economy, 81, 1017-32.

Holsapple, C., Johnson, L., Manakyan, H. and Tanner J. (1994) Business computing research journals: a normalized citation analysis, Journal of Management Information Systems, 11, $131-40$.

Kalaitzidakis, P., Mamuneas, T. P. and Stengos, T. (2001) Rankings of Academic journals and institutions in economics, Discussion Papers of the University of Cyprus, 10, 1-29.

Kalaitzidakis, P., Mamuneas, T. P. and Stengos, T. (2003) Rankings of academic journals and institutions in economics, Journal of the European Economic Association, 1, 1346-66.

Laband, D. and Piette, M. (1994) The relative impact of economic journals, Journal of Economic Literature, 32, 640-66.

Liebowitz, S. J. and Palmer, J. P. (1984) Assessing the relative impacts of economics journals, Journal of Economic Literature, 22, 77-88.

Moore, W. J. (1972) The relative quality of economics journals: a suggested rating system, Western Economic Journal, 10, 156-69. 